\title{
Bioética e vacinação infantil em massa
}

Sérgio de Castro Lessa ${ }^{1}$, José Garrofe Dórea ${ }^{2}$

\section{Resumo}

As vacinas são consideradas como uma das maiores conquistas da humanidade no controle e erradicação de doenças infectocontagiosas e também uma das técnicas biomédicas mais polêmicas e de maior controvérsia considerando os riscos de efeitos adversos e a sua forma compulsória de utilização em milhões de crianças saudáveis. $O$ atual paradigma preventivo de vacinação em massa tem sido desafiado nas últimas décadas por mudanças nas relações com a imunização, melhoria das condições sanitárias das populações e pelo surgimento de declarações universais de proteção do ser humano. Com isso, o presente artigo pretende analisar a vacinação infantil em massa sob a ótica da bioética no contexto individual e coletivo e criar um ambiente de discussão para reflexão ética sobre os programas de vacinação. Concluímos que a bioética em sua nova concepção conceitual propõe novos referenciais teóricos e metodológicos que podem ser utilizados para o debate ético das atuais políticas sanitárias.

Palavras-chave: Bioética. Vacinação em massa. Efeitos adversos. Política de saúde. Brasil

\section{Resumen}

\section{Bioética y la vacunación infantil masiva}

Las vacunas son uno de los mayores logros de la humanidad en el control y erradicación de las enfermedades infecciosas y también una de las técnicas biomédicas más discutidas y de mayor controversia teniendo en cuenta los riesgos de efectos adversos y su obligatoriedad de uso en millones de niños sanos. El paradigma actual de la vacunación masiva preventiva ha sido cuestionada en las últimas décadas por los cambios en las relaciones con la inmunización, la mejora de la salud de la población y la aparición de las declaraciones universales de protección humana. Por lo tanto, este artículo tiene como objetivo analizar la vacunación infantil masiva desde la perspectiva de la bioética en el contexto individual y colectivo y crear un ambiente propicio para la discusión de la reflexión ética sobre los programas de vacunación. Llegamos a la conclusión de que la bioética en su nuevo concepto propone nuevos marcos teóricos y metodológicos que se pueden utilizar para el debate ético de las políticas de salud actuales.

Palabras-clave: Bioética. Vacunación masiva. Efectos adversos. Políticas de salud. Brasil.

\section{Abstract \\ Bioethics and mass childhood vaccination}

Vaccines are considered one of the greatest achievements of mankind in the control and eradication of infectious diseases and also one of the most controversial biomedical techniques and greater controversy considering the risks of side effects and their compulsory use in millions of healthy children. The current paradigm of preventive mass vaccination has been challenged in recent decades by changes in relationships with immunization, improvement of sanitary condition of populations and the emergence of universal declarations for human protection. Thus, the present work aims to analyze the mass childhood vaccination from the perspective of bioethics in the individual and collective context and create an environment for discussion of ethical reflection on vaccination programs. We conclude that de new bioethics' approach proposes a new theoretical and methodological framework that can be used for the ethical debate of current health policies.

Key words: Bioethics. Mass vaccination. Adverse effects. Health policy. Brazil.

1. Doutor sclessa@hotmail.com 2. Doutor dorea@rudah.com.br - Universidade de Brasília (UnB), Brasília/DF, Brasil.

\section{Correspondência}

Sérgio de Castro Lessa. Quadra 12, Conj. C, Casa 34 CEP 73010-123. Sobradinho/DF, Brasil.

Declaram não haver conflito de interesse. 
As vacinas são consideradas como uma das tecnologias médicas mais efetivas e de menor custobenefício. Utilizadas em todo o mundo no controle e prevenção de doenças infecciosas, revelam-se importantes principalmente nos países em desenvolvimento, que possuem condições sanitárias deficientes e escassez de recursos destinados às ações de saúde pública. Por ser claramente uma das políticas e técnicas de segurança médica mais universais e globalizadas, parece difícil eliminar a atração ética exercida pela ideologia da vacinação para todas as idades, ambos os sexos, todas as etnias e todas as populações.

É indiscutível que as políticas de vacinação infantil compulsória contribuíram substancialmente para o sucesso das vacinas, resultando no aumento das imunizações e na consequente redução na incidência de doenças imunopreveníveis. Como estas doenças tornaram-se extremamente raras, e até mesmo desconhecidas pela maioria da população mundial, estabeleceu-se um paradoxo na conquista sanitária: a atenção do público não está mais centrada nas doenças imunopreveníveis, mas sim na segurança e eficácia das vacinas ${ }^{1}$. Com isso, a questão ética das vacinas tem se alterado ${ }^{2}$, considerando que são, por vezes, administradas compulsoriamente a crianças saudáveis sem a devida percepção do risco epidêmico ou de questões morais relacionadas, por exemplo, à autonomia e vulnerabilidade.

O sucesso de um programa de vacinação está diretamente relacionado não apenas ao aumento das taxas de cobertura vacinal, mas também à necessidade de que as vacinas possuam alto padrão de segurança e total aceitação pela população. Em países desenvolvidos, os temores dos efeitos adversos das vacinas tornaram-se mais evidentes com a diminuição da percepção de risco provocado pelas doenças imunopreveníveis ${ }^{3}$. Este fato levou à queda das taxas de cobertura vacinal e ao ressurgimento de doenças que já haviam sido controladas no passado ${ }^{4,5}$. Entretanto, os países mais pobres, cujas populações ainda vivem em contato direto com os problemas relacionados às doenças infectocontagiosas, são menos relutantes em assumir os riscos de se proteger por meio de vacinas.

A vacina, e principalmente a sua forma de utilização universal, parece ser a panaceia sanitária contemporânea para a resolução dos problemas antigos e atuais de saúde pública, quer para o enfrentamento de epidemias persistentes, emergentes, quer para doenças que só ouvimos falar nas enciclopédias de saúde humana. Esta guerra contra os germes, associada ao alarmismo pandêmico, tem provocado situações preocupantes.
Ao verificar aleatoriamente os cartões de vacina de crianças de 1 a 5 anos, comparando o número de doses recomendadas pelo fabricante em relação ao número de doses aplicadas, registrado no cartão, Nogueira ${ }^{6}$ constatou a tendência para extrapolar as doses consideradas suficientes à imunização. Ainda que o aumento do número de doses registrado refira-se apenas à vacina oral contra a poliomielite, que não traz risco às crianças que as recebem, o fato ilustra a tendência a extrapolar a prescrição indicada.

Contudo, este paradigma sanitário dominante tem sido desafiado nas últimas décadas por mudanças nas relações com a imunização ${ }^{7}$, melhoria das condições sanitárias das populações, efeitos adversos das vacinas e pelo surgimento de declarações universais de proteção do ser humano, a exemplo da Declaração Universal sobre Bioética e Direitos Humanos $^{8}$ - acontecimentos que criam um ambiente para discussão ética sobre as atuais políticas sanitárias adotadas pelos países.

Dessa forma, o presente artigo pretende analisar o atual modelo de vacinação infantil em massa sob a ótica da bioética. Para isso, considerando a estreita relação médico/profissional de saúde versus paciente, utilizaremos a corrente principialista ${ }^{9}$, que apesar de não ser unânime nem mesmo em seu país de origem para a resolução de conflitos nestas relações ${ }^{10}$ foi criada como referencial teórico para defender os indivíduos mais frágeis nas relações entre profissionais de saúde e seus pacientes. Utilizaremos também outra abordagem teórica da bioética mais relacionada com a dimensão social da saúde e que considera em suas reflexões morais a fragilidade e vulnerabilidade de grupos ou segmentos sociais como proposta epistemológica anti-hegemônica, ampliada e politizada ${ }^{11}$.

\section{Vacinas e ética: incertezas, controvérsias e conflitos}

Em qualquer parte do mundo, será extremamente improvável, hoje em dia, encontrar alguém que jamais tenha sido tocado pela questão da vacinação, sobretudo a vacinação promovida ou mesmo imposta pelo Estado. Dessa forma, os conflitos éticos das vacinas associados à sua forma universal e compulsória de administração demonstram as dificuldades de se ter um julgamento absoluto sobre os fundamentos racionais da vacinação e do interrelacionamento entre o campo das ciências humanas e biomédicas. 
O mundo tem passado por profunda mutação tecnocientífica, cultural e ética. É neste horizonte que podem ser encontrados diversos fatores particulares que fundamentam uma análise moral da vacinação, como, por exemplo, a imprevisibilidade de seu efeito no organismo humano a longo prazo, a emergência de declarações universais de proteção aos direitos humanos, a modificação da relação médico-paciente, o pluralismo moral contemporâneo e o conflito de interesse individual e coletivo.

A descoberta das vacinas tem importância crucial na história da ética médica. No final do século XVIII, em meio a uma epidemia de varíola, o médico inglês Edward Jenner, em uma experiência revolucionária, inoculou a linfa das lesões de uma ordenhadora de vacas em um garoto, James Phillip. Após algum tempo, Jenner inoculou-lhe mais de uma vez o fluido extraído de uma lesão variolosa. 0 menino resistiu e não apresentou a doença, comprovando a eficácia de sua tese acerca da técnica de imunização ${ }^{12}$. Esta experiência de Jenner, apesar de parecer antiética na perspectiva atual, não levantou qualquer dilema moral à época ${ }^{13}$ dado que o terror à varíola era disseminado, por ser considerada a mais terrível doença do século XVIII, que dizimou populações inteiras.

Estes fatos ocorridos com a descoberta das vacinas nos levam ao questionamento sobre o contexto em que foram testadas e aceitas pela população no passado e de como são consideradas e utilizadas no presente. A análise bioética da vacinação permite uma visão ampliada de uma realidade concreta e complexa, indo além da análise reduzida e disciplinar, tornando-a mais interessante e, também, mais instigante. Como frisou Moulin ${ }^{14}$, este enfoque é importante não como mecanismo de controle, mas poderá servir também como uma resposta a um procedimento médico que pode ser falivel ou incompletamente validado, inoportunamente aplicado e não raro mal explicado e comentado.

É necessário contrabalancear a história triunfalista da vacinação como ciência e tecnologia médica com o exame atento e minucioso de seu impacto e suas consequências futuras no sujeito humano como ser moral. Apesar desta glória reconhecida e incontestável conseguida ao longo dos tempos, as vacinas também são consideradas como uma das técnicas biomédicas mais polêmicas, suscitando calorosos debates científico e ético. A eficácia e segurança das vacinas, assim como dos programas de imunização implementados pelos governos, e as injustiças de acesso desigual aos custos e benefícios da vacinação foram entrelaçados ao longo da história das vacinas e permanecem controversos até hoje ${ }^{15}$.
A atual condição sanitária global logra êxito e credibilidade às vacinas. Entretanto, segundo Bazin ${ }^{16}$, a erradicação de doenças, como a varíola e, provavelmente, em breve, a poliomielite, foi e será devida à higiene associada à vacinação em países desenvolvidos, mas apenas pela vacinação em países pobres que não têm acesso à água potável e não podem eliminar seus resíduos de forma adequada. Esta tese parece ser verdadeira quando consideramos que algumas doenças, para as quais ainda não há vacinas, tais como cólera, dengue, doença de Chagas, somente existem em países mais pobres que possuem condições sanitárias deficientes. Para Holland ${ }^{17}$, os programas de vacinação em massa são controversos porque sua justificativa depende de qual sentido de saúde está em jogo.

Uma das questões polêmicas e que diz respeito à segurança das vacinas refere-se à presença de conservantes e adjuvantes em sua composição, que são utilizados para reduzir o custo econômico das indústrias farmacêuticas, posto que o adjuvante permite utilizar menor quantidade de antígeno em cada dose e os conservantes são empregados para prevenir a contaminação bacteriológica e fúngica nas apresentações multidoses, uma vez que fabricar vacinas em monodoses é mais oneroso em face da necessidade de múltiplas embalagens, além de outros problemas relacionados ao armazenamento, conservação e transporte para os locais de aplicação.

As incertezas e controvérsias sobre a segurança das vacinas tiveram repercussão mundial após a publicação de artigo de Wakefield ${ }^{18}$ na revista Lancet, postulando que a vacinação contra o sarampo, caxumba e rubéola (MMR) poderia estar casualmente vinculada ao autismo devido à associação temporal existente entre a idade em que as crianças são vacinadas e a idade em que se inicia o surgimento desta doença. $\mathrm{O}$ artigo de Wakefield foi desacreditado (inclusive por envolver fraude científica) e retirado do rol de artigos publicados pela Lancet (retracted). Apesar disso, serviu para que vários pesquisadores iniciassem estudos para avaliar o efeito dos conservantes e adjuvantes nas vacinas - que até o momento vêm demonstrando não existir evidência científica para esta associação ${ }^{19-23}$.

Outro argumento é o de que a vacinação rotineira de crianças com vacinas contendo timerosal (VCT), que possuem conservante à base de mercúrio e são administradas logo após o nascimento, poderia expor os recém-nascidos a níveis inseguros de etilmercúrio ${ }^{24,25}$. Apesar do consenso entre a Organização Mundial da Saúde (OMS) e a Academia Americana de Pediatria quanto a ser desprezível o 
risco do timerosal na quantidade presente nas vacinas, estudos realizados para avaliar a toxicidade do mercúrio em forma de timerosal ${ }^{26-31}$ não consideram a relação entre a exposição iatrogênica do mercúrio por meio das vacinas à exposição alimentar, como no leite materno ou peixe, o que tem sido pesquisado por grupos no Brasil e em outros países. Por precaução, alguns países, como os Estados Unidos da América (EUA), não mais utilizam timerosal em suas vacinas. $O$ Chile está com um projeto no Senado para retirá-lo ${ }^{32}$.

A dose mais desafiadora dos programas de imunização compulsória é que, devido à pequena massa corporal dos bebês, o impacto do mercúrio administrado por algumas vacinas, como a de hepatite $B$ nas primeiras 12 horas de vida, equivale ao dobro das doses somadas das vacinas DTP e hepatite $B$ recebidas aos seis meses de idade. Com isso, substancial quantidade de crianças no mundo inteiro está recebendo, por meio das vacinas, doses de mercúrio acima do limite considerado seguro. Mas países como Hungria, Japão, Holanda, Suécia, Suíça e Inglaterra não utilizam a vacina de hepatite $B$ em seus calendários de vacinação infantil ${ }^{33}$.

Como consequência destas incertezas, o fato é que as vacinas monovalentes ou multivalentes utilizadas nos EUA e na Europa em seus programas de vacinação infantil são livres de timerosal desde $2004^{34}$. Entretanto, a maioria dos países ainda utiliza VCT em seus programas de imunização infantil por recomendação da OMS ${ }^{35}$, incluindo o Brasil. Com isso, as populações dos "países periféricos" não recebem as mesmas vacinas utilizadas em países com melhor fiscalização ou com serviços privados mais refinados. Considerando que a vacinação universal é uma prática globalizada e que os agentes infecciosos que acometem a população mundial são os mesmos, por que há diferença entre os tipos de vacinas aplicadas entre países pobres e ricos?

Não há dúvidas de que numa população altamente imunizada o risco de adquirir determinada doença é extremamente baixo. Entretanto, para algumas doenças, como a poliomielite, a expectativa de ocorrência de casos de paralisias associados ao vírus vacinal possui risco esperado e assumido pelo programa de erradicação global da poliomielite ${ }^{36}$. Para o Advisory Committee on Poliomyelitis Eradication (ACPE) ${ }^{37}$, a reintrodução continuada do poliovírus atenuado por meio de vacinas em um mundo livre de pólio resulta em casos de poliomielite causados pela vacinação. Este risco não só é inquietante como necessita ampla discussão e conhecimento por parte da sociedade e dos governos que adotam essas estratégias. A presença de casos de paralisia provocados pela mesma política vacinal que objetiva a erradicação constitui-se no principal dilema técnico e ético da fase pós-eliminação da poliomielite ${ }^{38}$. O Brasil demonstrou avanço no tocante à vacinação contra a paralisia infantil, pois incluiu no calendário de vacinação infantil de 2012 a vacina poliomielite inativada injetável ${ }^{39}$, que será substituída pela vacina oral atenuada, utilizada nos EUA desde o ano $2000^{40}$

Outra questão que apresenta forte dilema ético diz respeito ao uso de vacinas obrigatórias no calendário de vacinação contra doenças específicas de determinada faixa etária ou determinado grupo de risco exposto ${ }^{41-43}$. Nos EUA, a instituição da vacinação compulsória contra o papiloma vírus humano (HPV) em crianças de 11 a 12 anos tem sido motivo de grandes debates éticos, vez que a eficácia da vacina é maior em pessoas que ainda não são sexualmente ativas ${ }^{44}$. Obrigar a imunização de populações inteiras que não estão sob o mesmo risco de adquirir ou transmitir doenças constitui um contrassenso ético. Neste caso, um dos principais argumentos contra esta prática é de que os riscos de exposição e/ou de adquirir certos tipos de doença são diferenciados, pois sofrem influência de vários fatores, e que no caso de doenças comuns não há porque assumir qualquer nível de risco de algum efeito adverso da vacina ${ }^{45}$.

É fato que os riscos das vacinas são conhecidos desde os primórdios de seu uso, em um contexto sanitário daquela época cujas epidemias ainda dizimavam populações. Porém, nos países em desenvolvimento, como o Brasil, estas questões ainda não tiveram a mesma atenção dispensada pelos países desenvolvidos, posto que o foco do governo se concentra especialmente em manter os altos índices de cobertura vacinal ou em questões persistentes relacionadas à exclusão social, distribuição de renda e acesso aos serviços básicos de saúde - as quais ainda fazem parte do rol de demandas da maioria da população.

\section{Vacinação e bioética principialista}

Recentemente, tem ocorrido grande interesse da ética para as questões de saúde pública fundamentada em uma responsabilidade social de proteger e promover a saúde da população como um todo ${ }^{46}$. Entretanto, principalmente nas questões sanitárias, a saúde pública e a medicina preventiva têm sido áreas negligenciadas em bioética, a qual 
possui maior foco nos interesses, direitos e obrigações coletivos do que nos interesses e valores individuais ${ }^{47}$.

No campo das chamadas éticas aplicadas, a bioética surgiu para dar conta dos conflitos morais e problemas éticos surgidos no âmbito das ações em saúde e das ciências biomédicas. Dessa forma, entendemos que, a princípio, a bioética pode ser considerada como uma ferramenta legítima e eficiente para a análise crítica da moralidade das práticas vacinatórias contemporâneas e como auxílio para as tomadas de decisão, eticamente justificadas, por ações de saúde que garantam a distribuição equânime tanto dos benefícios quanto dos eventuais riscos da vacinação.

A corrente da bioética principialista, que se tornou clássica, centra-se sobretudo em alguns princípios morais cuja aplicação supostamente leva à solução dos dilemas éticos na saúde: autonomia, beneficência, não maleficência e justiça. Estes quatro princípios funcionam, a grosso modo, como obrigação prima facie. Como não é incomum que entrem em conflito, principalmente no contexto de ações coletivas, a análise moral de uma ação considera que os diferentes valores e interesses devem ser contrabalanceados para que os agentes morais, eventualmente, sejam capazes de alcançar uma conclusão de como devem agir ${ }^{9}$.

Limites tênues entre beneficência e não maleficência da vacinação em massa

Várias ações preventivas de uso rotineiro, a exemplo da vacinação, implicam em algum grau de risco para os pacientes. No contexto da bioética principialista, se faz necessário respeitar o princípio da não maleficência, haja vista que os agentes de saúde possuem o princípio ético de não provocar danos a seus pacientes (primum non nocere). Em paralelo, como as atividades preventivas visam, em primeira instância, a proteção das pessoas contra doenças infecciosas, partimos do princípio de que o procedimento de vacinação também cumpre o princípio da beneficência. Neste caso, considerando que é moralmente indesejável causar danos às pessoas, quer pela exposição aos riscos dos efeitos adversos da vacinação quer pela exposição às doenças pela falta de imunização, que princípio moral deve ser considerado quando os riscos e os benefícios da vacinação são distribuídos de forma desigual entre a população?

Em várias situações práticas não faz sentido o equilíbrio entre princípios muito diferentes porque muitos princípios ou valores são incomparáveis. Isto ocorre nos casos em que uma determinada ação é a melhor em algum contexto relevante, enquanto outra é melhor em relação a outro contexto relevante, mas não há uma verdade óbvia sobre como devem ser comparadas considerando todos os contextos relevantes - nesta circunstância, as ações estão "em pé de igualdade" ou de paridade ${ }^{48}$. Como exemplo, podemos citar a vacina contra gripe pandêmica, cujos princípios morais ou valores relacionados com sua administração são díspares. Neste caso, por que devemos acreditar que proteger as crianças do risco de adquirir uma gripe é mais importante do que protegê-las do risco de serem acometidas com algum efeito adverso da vacina? ${ }^{49}$.

Como as vacinas não são $100 \%$ eficazes ${ }^{50}$, não se pode afirmar com absoluta certeza de que um indivíduo não adquiriu certa doença devido à imunidade adquirida pela vacina ou devido à imunidade coletiva, vez que existem vários fatores que influenciam a obtenção desta imunidade. Paralelamente, quando uma criança sadia é vacinada visa-se, inicialmente, protegê-la contra determinada doença. Entretanto, considerando que as vacinas não são $100 \%$ seguras, eventos adversos pós-vacinação (EAPV) podem ocorrer ${ }^{51}$. Neste caso, uma ação inicial que visava cumprir o princípio da beneficência passa a não atender ao princípio da não maleficência. $O$ dilema moral existente seria o de que não vacinar significa, por um lado, não submeter as crianças aos riscos de EAPV, mas, por outro, submetê-las ao risco de adquirir doenças imunopreveníveis. Assim, surgem conflitos entre princípios, porque determinado princípio ético é definido com base nos resultados pretendidos de uma ação, não considerando os possíveis efeitos dela resultantes.

\section{Liberdade individual versus responsabilidade cole- tiva}

A questão da autonomia dos pacientes já faz parte da discussão interna da ética médica em diversos países. O princípio da autonomia vem sendo aceito pelos médicos, por ser considerado essencial para o consentimento livre e informado, o qual, por sua vez, é a base dos códigos de ética médica vigentes e de resoluções relativas à pesquisa em seres humanos ${ }^{52}$. Ao contrário da prática clínica, cuja noção de autonomia é invocada para exprimir a liberdade do sujeito de consentir ou recusar um tratamento proposto por um médico, no âmbito da saúde pública, particularmente nos casos de vacinação em massa nas situações de epidemia, a autonomia do sujeito está em conflito com o interesse da proteção cole- 
tiva, pois a não violação da autonomia individual implicaria em um risco real para toda a comunidade ${ }^{53}$. Em tal circunstância, qual é o valor da autonomia quando a saúde da coletividade está em risco?

Em muitas situações, em que um bem comum está em jogo, o interesse coletivo passa a ter prioridade sobre o interesse individual, como, por exemplo, nas situações de epidemias, cuja rígida restrição das liberdades individuais pode ser legítima, valendo o princípio da proteção do 'corpo social' contra as ameaças de indivíduos e grupos que possam prejudicá-lo ${ }^{54}$. Entretanto, Fine ${ }^{55}$ contra-argumenta que a proteção coletiva por meio de vacinação compulsória possui consequências éticas e legais, pois fornece proteção indireta às pessoas que não foram vacinadas e exposição aos riscos das vacinas, mesmo que pequeno, a alguns indivíduos para o benefício de outros. Isso pode ter várias implicações, as quais se diferenciam em diferentes contextos culturais, éticos e legais no que diz respeito à responsabilidade do governo frente às circunstâncias da ocorrência de efeitos adversos das vacinas. Sob esta perspectiva, verifica-se que a proteção indireta, a base da imunidade coletiva, levanta questões éticas importantes sobre os valores individuais e coletivos.

O direito de autodeterminação é correlato à obrigação de não prejudicar outros. O respeito à autonomia tem, portanto, validade prima facie e pode ser sobrepujado por considerações morais concorrentes. A obrigação de respeito à autonomia, apesar de ampla, não se aplica a pessoas não autônomas, pois são imaturas, ignorantes e coagidas ou exploradas. São exemplos crianças e pacientes com deficiência mental, que têm a competência diminuída. Assim, a autonomia não se limita ao doente, mas se estende à sua família ${ }^{56}$. Neste caso, a prioridade léxica da autonomia de um indivíduo ou seu responsável de recusa à vacinação não vale necessariamente, podendo ceder o passo ao princípio da beneficência ao próprio indivíduo e ao coletivo.

Segundo Bradley ${ }^{57}$, particularmente no caso de vacinação infantil não há que se falar em autonomia, mas em direitos. $O$ autor questiona se uma abordagem baseada em direitos resolveria o dilema da vacinação obrigatória na infância, pois não é fácil priorizar os direitos da criança em receber os cuidados de saúde com os direitos dos pais de educar seus filhos segundo as próprias convicções e o direito de a população ser protegida contra doenças infecciosas preveníveis por vacinas. Assim, se adequados níveis de proteção podem ser adquiridos por outros meios, a vacinação compulsória contra a vontade dos pais não pode ser justificada se o benefício para a criança é insignificante.

No contexto dos programas de vacinação em massa, o direito à autonomia é baseado no reconhecimento social do respeito a este princípio. Considerando que as vacinas não são totalmente seguras, 0 respeito à autonomia dita que os riscos não devem ser impostos aos indivíduos sem o consentimento deles. Neste caso, há uma razão crítica para avaliar os argumentos prós e contra o direito de consentir ou recusar, uma vez que este pode afetar seriamente a saúde das pessoas ${ }^{58}$.

As restrições aos direitos individuais no âmbito dos programas de vacinação são justificadas por duas razões: em função do benefício ao próprio indivíduo ou em função do benefício à coletividade. Muitos países possuem programas de vacinação coletiva que foram implementados com o argumento de proteger a comunidade contra doenças infecciosas, considerando o risco potencial das pessoas que não foram vacinadas por algum motivo e daqueles que se vacinaram, mas que não foram devidamente protegidos.

O sucesso de um programa de vacinação em massa depende do número de indivíduos imunizados. Assim, quanto maior a cobertura vacinal, menor é a probabilidade de propagação do agente infeccioso, principalmente nos grupos vulneráveis, como crianças e idosos. Neste contexto, a não vacinação individual é indesejável, pois aqueles indivíduos que decidiram não se vacinar possuem maior risco do que aqueles que optaram pela vacinação. Neste caso, em que há uma evidente tensão entre o interesse individual e o coletivo, a autonomia perde valor frente aos interesses de imunidade da coletividade. Na ótica principialista, atender ao princípio da autonomia, que faculta ao indivíduo tomar ou não a vacina, se opõe ao princípio da não maleficência de por em risco a coletividade.

No contexto da saúde pública, as políticas de vacinação podem considerar razoável supor que a proteção das populações tenha uma prioridade léxica sobre o exercício da autonomia pessoal. Entretanto, há um conflito ético entre a autonomia individual e o bem coletivo, o que torna frágil o argumento moral da responsabilidade individual em ações coletivas.

\section{Princípio da justiça}

Qual é o conceito de justiça, no âmbito dos programas de vacinação em massa? Para Duran ${ }^{59}$, em bioética fala-se muito da justiça distributiva, 
que diz respeito à justa repartição dos encargos e vantagens da vida social. De modo mais concreto, designa, por um lado, a distribuição equitativa tanto dos custos quanto dos benefícios na sociedade; por outro, o justo acesso a esses recursos.

No contexto das políticas de vacinação, a justiça distributiva designa o acesso de todas as crianças a vacinas seguras e eficazes. Paradoxalmente, apesar de haver igualdade no acesso às vacinas, não há equidade na distribuição dos custos da vacinação, haja vista que na vacinação coletiva é improvável que uma pessoa se beneficie mais do que a outra, vez que a distribuição dos benefícios não pode ser alocada injustamente. Paralelamente, há situações em que grupos de indivíduos arquem com o ônus da vacinação em favor de outro grupo que não foi vacinado ${ }^{60,61}$. Apesar de, no contexto coletivo, considerar-se que estes pequenos riscos são equilibrados pelos beneficios da imunização da população geral, um indivíduo ocasionalmente carrega o ônus da ocorrência de um EAPV para o benefício geral da população.

Vários países possuem programas de compensação de EAPV que são implementados independentemente de culpa "No-fault compensation" 62. Esses programas são executados no âmbito de uma instância administrativa do governo, com o objetivo de garantir e promover tratamento equânime, transparência e justiça às crianças acometidas com EAPV de vacinas utilizadas nos programas de vacinação coletiva ${ }^{63}$. Com isso, remove-se a incerteza das ações judiciais que são uma via extensa e restrita, muitas vezes inacessíveis à maioria dos indivíduos de baixa renda que tomam vacina ${ }^{64}$.

O Brasil, a despeito de ter um dos mais bemsucedidos programas de imunização do mundo, não possui nenhuma iniciativa para compensar ou atender de forma diferenciada as crianças acometidas com EAPV, criando um grupo de "desassistidos" do sistema oficial de saúde pública, restando apenas a "via crucis" do Judiciário como única alternativa para a busca por justiça ${ }^{65-68}$. Mesmo nos casos de pólio pós-vacinal encontram-se na jurisprudência brasileira decisões que excluem a responsabilidade do Estado - a exemplo da Apelação Cível 639.645-5/6 ${ }^{69}$, que indeferiu ação de indenização por danos morais e materiais contra criança que havia sido vacinada na campanha de vacinação contra a poliomielite. Para o tribunal as reações pós-vacinação configuram risco da própria imunização, obrigatória em virtude de lei nacional, acentuado por fatores de ordem sanitária ${ }^{69}$.

Com isso, as atuais políticas de imunização infantil não atendem plenamente aos princípios da equidade, universalidade e integralidade na as- sistência à saúde, apesar de encontrarem-se explicitamente dispostas como princípios doutrinários na Lei Orgânica da Saúde (LOS) que regulamenta o Sistema Único de Saúde (SUS) brasileiro. Assim, em nosso contexto de análise, temos a convicção de que o conceito de justiça distributiva da bioética principialista não é suficiente ou capaz de garantir a equidade na distribuição dos encargos das políticas de vacinação infantil.

\section{Limitações do principialismo e o novo paradig- ma da bioética}

A teoria principialista, revisada por seus próprios proponentes na $5^{\text {a }}$ edição do livro Principles of biomedical ethics ${ }^{9}$, apesar de sua reconhecida praticidade e utilidade para a análise da vacinação no contexto individual, demonstra-se insuficiente para a análise no contexto coletivo das ações de saúde pública. Esta limitação tem sido constantemente debatida por bioeticistas da América Latina no conjunto de macroproblemas bioéticos persistentes ou cotidianos enfrentados por grande parte da população de países com significativos índices de exclusão social, como o Brasil e seus vizinhos da América Latina ${ }^{70}$.

Considerando as especificidades das ações em saúde pública, surgem indagações se é suficientemente adequado adaptar ao contexto coletivo o modelo dos quatro princípios da bioética principialista como ferramenta para entender e discutir os conflitos morais que ocorrem nas ações coletivas ${ }^{71}$. A inaplicabilidade do modelo principialista para a análise da vacinação infantil em massa ficou evidenciada pela ocorrência de uma tensão entre princípios, como aponta Schramm ${ }^{72}$.

No que diz respeito às questões relacionadas aos riscos versus benefício das vacinas e de seu uso universal e compulsório em toda a população, portanto relacionados à saúde pública, é importante notar que o foco são as relações entre o Estado, o indivíduo e o coletivo. Em consequência, faz-se necessário definir quais ferramentas conceituais poderiam ser utilizadas na abordagem desses problemas para proporcionar impactos positivos nos grupos mais vulneráveis, vulnerados e excluídos - e consequentemente, nas suas organizações políticas e administrativas.

Nos programas de imunização em massa, que visam em última instância a proteção coletiva, os efeitos desejáveis no indivíduo não possuem o mesmo valor ético dos efeitos no coletivo, levando a um desequilíbrio entre o custo/benefício individual em 
relação ao custo/benefício coletivo. Dessa forma, considerando os conflitos morais entre o individual $\mathrm{e}$ o coletivo, o desequilíbrio entre o custo/benefício e a incapacidade ou insuficiência da bioética principialista aplicada stricto sensu, se faz preciso o uso de outros valores e princípios morais - como, por exemplo, a responsabilidade, solidariedade e justiça social como ferramenta para reflexão dos problemas éticos relacionados aos programas de vacinação infantil.

Nos últimos anos, a bioética conheceu um desenvolvimento importante nos países da América do Sul com a consolidação de uma perspectiva contextualizada e politizada que pudesse responder à realidade dos países periféricos no contexto mundial, configurando-se em instrumento eficaz para mediar os conflitos emergentes e, principalmente, os persistentes, que continuam marcando de maneira aviltante a maioria da sociedade nas referidas nações ${ }^{73}$.

A bioética teve grande modificação conceitual quando a Organização das Nações Unidas para a Educação, a Ciência e a Cultura (Unesco) publicou, em 2005, a Declaração Universal sobre Bioética e Direitos Humanos, incorporando e politizando as questões sanitárias, sociais e ambientais em seu contexto. A América Latina teve papel fundamental para a consolidação deste documento como referência para a bioética internacional, cujas negociações foram marcadas por um árduo caminho de discussão e convencimento, apesar dos protestos dos setores mais tradicionais e conservadores da bioética ${ }^{74}$.

Este novo conceito para a bioética surgiu na América Latina como uma proposta epistemológica anti-hegemônica ao principialismo, que segundo Garrafa e Porto ${ }^{75}$ propõe uma aliança concreta com o lado historicamente mais frágil da sociedade. Esta corrente da bioética pretende legitimar, no campo de estudo das moralidades e da aplicação dos valores éticos, uma perspectiva ampla que envolva os aspectos sociais da produção das doenças, contribuindo para a construção de uma bioética crítica que possa ser aplicada nos países periféricos e, especialmente, no Brasil.

O conceito de proteção inserido nesta nova abordagem da bioética por pesquisadores latinoamericanos considera os problemas morais envolvidos pela vulneração humana, ou seja, a condição existencial dos humanos que não estão submetidos somente a riscos de vulneração, mas a danos e carências concretas, constatáveis por qualquer observador racional e imparcial. O princípio moral de proteção está implícito nas obrigações do Estado, que deve proteger seus cidadãos contra calamidades, guerras etc., uma vez que todos os cidadãos não conseguem se proteger sozinhos contra tudo e todos, podendo tornar-se suscetíveis e até vulnerados em determinadas circunstâncias.

A criança possui uma condição de vulnerabilidade nata que é uma condição natural de qualquer ser vivo e, portanto, característica universal que não pode ser plenamente protegida. Quando acometida por uma reação adversa à vacina, passou de vulnerável para vulnerada, ou seja, diretamente afetada. Portanto, conforme Schramm ${ }^{76}$ destaca, dever-se-ia distinguir graus de proteção de acordo com a condição existencial de vulnerabilidade, suscetibilidade e vulneração, a qual poderia ser considerada na elaboração e implementação de políticas públicas de compensação.

\section{Considerações finais}

Ficou demonstrado neste artigo que a bioética principialista não é suficiente ou adequada para a análise das questões éticas envolvidas em ações individuais que possuem impacto significativo na saúde do coletivo, como é o caso da vacinação infantil em massa. $O$ conflito de interesse individual e coletivo, a distribuição desigual do risco versus benefício e a condição de vulnerabilidade da criança abrem espaço para a reflexão ética dos atuais programas de vacinação utilizados pelos governos e cria um ambiente de reflexão e fundamentação para o aperfeiçoamento das políticas de saúde pública.

A abordagem social e politizada da bioética idealizada pelos países latino-americanos vai ao encontro desta reflexão teórica e necessidade prática de ação. Esta visão amplificada da bioética permite a análise das ações públicas e coletivas em saúde, no sentido de também considerar questões sociais, ambientais, econômicas e políticas. Isso permitirá, por exemplo, que o país avance nas discussões para a implementação de medidas compensatórias aos EAPV, a exemplo de como é feito atualmente em outros países e no Brasil, nos casos de acidentes de trânsito ou de desastres ambientais.

Nesse sentido, a análise dos programas de vacinação em massa, em uma perspectiva ampliada da bioética, será capaz de entender a complexidade do tema, o rigor da prevenção, o reconhecimento da vulnerabilidade e o respeito à alteridade, remetendo a uma noção de responsabilidade coletiva solidária que servirá como pressuposto ao Estado para a implantação de medidas compensatórias ao amparo às crianças acometidas por reações às vacinas compulsoriamente administradas em benefício da saúde pública. 


\section{Referências}

1. Gellin BG, Maibach EW, Marcuse EK. Do parents understand immunizations? A national telephone survey. Pediatrics. 2000;106(5):1.097-102.

2. Bazin $\mathrm{H}$. The ethics of vaccine usage in society: lessons from the past. Commentary. Curr Opin Immunol. 2001;13(4):505-10.

3. Chen RT. Vaccine risks: real, perceived and unknown. Vaccine. 1999;17(3 Suppl):S41-46.

4. Ellenberg SS, Chen RT. The complicated task of monitoring vaccine safety. Public Health Rep. 1997;112(1):10-20.

5. Gangarosa EJ, Galazka AM, Wolfe CR, Phillips LM, Gangarosa RE, Miller E et al. Impact of antivaccine movements on pertussis control: the untold story. Lancet. 1998;351(9099):356-61.

6. Nogueira R. Medicina social. Brasilia: Ed. Rui Nogueira; 2011.

7. Cunha M, Durand J-Y. Nas fronteiras do corpo, do saber e do Estado: vacinação e sociedade. In: Cunha, M, Cunha L, organizadores. Intersecções ibéricas: margens, passagens e fronteiras. Lisboa: $90^{\circ}$ Graus Editora; 2008. p. 369-76.

8. Organização das Nações Unidas para a Educação, a Ciência e a Cultura. Declaração Universal sobre Bioética e Direitos Humanos. [Internet]. [acesso jul. 2012]. Genebra: Unesco; 2005. Disponível: http://unesdoc.unesco.org/images/0014/001461/146180por.pdf

9. Beauchamp T, Childress JF. Principles of biomedical ethics. $5^{\mathrm{a}}$ ed. Oxford: Oxford University Press; 2001.

10. Clouser KD, Gert B. A critique of principlism. J Med Philos. 1990;15(2):219-36.

11. Garrafa V. Ampliação e politização do conceito internacional de bioética. Rev. bioét. (Impr.). 2012;20(1):9-20.

12. Stern AM, Markel $H$. The history of vaccines and immunization: familiar patterns, new challenges. Health Affairs. 2005;24(3):611-21.

13. Moore J. The history of the small pox. London: Longman, Hurst, Rees and Orme and Brown; 1815. p. 312.

14. Moulin AM. A hipótese vacinal: por uma abordagem crítica e antropológica de um fenômeno histórico. Hist Ciênc Saúde-Manguinhos. 2003;10(2 Suppl):S499-517.

15. Grady C. Ethics of vaccine research. Nat Immunol. 2004;5(5):465-8.

16. Bazin H. A brief history of the prevention of infectious diseases by immunisations. Comp Immunol Microbiol Infect Dis. 2003;26(5-6):293-308.

17. Holland SM. Public health ethics. Cambridge: Polity Press; 2007.

18. Wakefield AJ, Murch SH, Anthony A, Casson DM, Malik M, Berelowitz M et al. Ileal-lymphoidnodular hyperplasia, non-specific colitis, and pervasive developmental disorder in children. Lancet. 1998;351(9103):637-41.

19. Bedford H, Booy R, Dunn D, DiGuiseppi C, Gibb D, Gilbert R et al. Autism, inflammatory bowel disease, and MMR vaccine. Lancet. 1998;351(9106):908.

20. Schultz ST. Does thimerosal or other mercury exposure increase the risk for autism? A review of current literature. Acta Neurobiol Exp (Wars). 2010;70(2):187-95.

21. Taylor B, Miller E, Farrington CP, Petropoulos MC, Favot-Mayaud I, Li J et al. Autism and measles, mumps, and rubella vaccine: no epidemiological evidence for a causal association. Lancet. 1999;353(9169):2026-9.

22. Andrews N, Miller E, Grant A, Stowe J, Osborne V, Taylor B. Thimerosal exposure in infants and developmental disorders: a retrospective cohort study in the United Kingdom does not support a causal association. Pediatrics. 2004;114(3):584-91.

23. Mrozek-Budzyn D, Majewska R, Kiełtyka A, Augustyniak M. Lack of association between thimerosal-containing vaccines and autism. Przegl Epidemiol. 2011;65(3):491-5.

24. Coleman E. Ethylmercury in vaccines. Pediatrics. 2003;111:922-3.

25. Dórea JG, Bezerra VL, Fajon V, Horvat M. Speciation of methyl- and ethyl-mercury in hair of breastfed infants acutely exposed to thimerosal-containing vaccines. Clin Chim Acta. 2011;412(1718):1563-6.

26. Burbacher TM, Shen DD, Liberato N, Grant KS, Cernichiari E, Clarkson T. Comparison of blood and brain mercury levels in infant monkeys exposed to methylmercury or vaccines containing thimerosal. Environ Health Perspect. 2005;113(8):1015-21.

27. Dórea JG. Exposure to mercury during the first six months via human milk and vaccines: modifying risk factors. Am J Perinatol. 2007;24(7):387-400.

28. Dórea JG. Mercury and lead during breast-feeding. Br J Nutr. 2004;92:21-40.

29. Dórea JG, Barbosa AC, Ferrari I, De Souza JR. Fish consumption (hair mercury) and nutritional status of Amazonian Amer-Indian children. Am J Hum Biol. 2005;17(4):507-14.

30. Dórea JG, Barbosa AC, Ferrari I, Souza JR. Mercury in hair and in fish consumed by riparian women of the Rio Negro, Amazon, Brazil. Int J Environ Health Res. 2003;13(3):239-48.

31. Dórea JG, Moreira MB, East G, Barbosa AC. Selenium and mercury concentrations in some fish species of the Madeira River, Amazon Basin, Brazil. Biol Trace Elem Res. 1998;65(3):211-20.

32. Dubreuil CGC, Navarro JAU. Trazas. El peligro del mercurio en las vacunas: responsabilidad del estado de Chile por el actuar de sus órganos. BuenasTareas.com. [Internet]. jun. 2012 [acesso jul. 2012]. Disponível: http://www.buenastareas.com/ensayos/Trazas/4680353.html 
33. United Nations Children's Fund. Immunization summary: a statistical reference containing data through 2010. [Internet]. jul. 2012 [acesso jul. 2012]. Disponível: http://www.childinfo.org/files/ immunization_summary_en.pdf

34. American Academy of Pediatrics and the Public Health Service. Thimerosal in vaccines: a joint statement of the American Academy of Pediatrics and the Public Health Service. MMWR Morb Mortal Wkly Rep. 1999;48(26):563-5.

35. World Health Organization. Who child growth standards: length/height-for-age, weight-for-age, weight-forlength, weight-for-height and body mass index-for-age: methods and development. [Internet]. Geneva: WHO; 2006 [acesso jul. 2012]. Disponível: http://www.who.int/childgrowth/ standards/technical_report/en/

36. World Health Organization. Global Polio Eradication Initiative Annual Report 2011. [Internet]. Geneva: WHO; 2011 [acesso jul. 2012]. Disponível:http://www.polioeradication.org/Aboutus/ Annualreports.aspx

37. World Health Organization. Advisory Committee on Poliomyelitis Eradication Reports. [Internet]. Geneva: WHO; 2004 [acesso jul. 2012]. Disponível: http://www.polioeradication.org/ Resourcelibrary/Advisoryandcertification/AdvisoryCommitteeonPoliomyelitisEradication.aspx

38. Teixeira-Rocha ES, Carmo EH, Tavares-Neto J. Ocorrência de poliomielite associada à vacina no Brasil, 1995 a 2001. Rev Panam Salud Publica. 2005;18(1):21-4.

39. Brasil. Ministério da Saúde. Ministro lança campanha para atualizar caderneta de vacinação. [Internet]. 14 ago. 2012 [acesso 18 ago. 2012]. Disponível: http://portalsaude.saude.gov. $\mathrm{br} /$ portalsaude/noticia/6633/162/ministro-lanca-campanha-para-atualizar-caderneta-devacinacao.html

40. Centers for Disease Control and Prevention. Vaccines and preventable diseases: polio vaccination. [Internet]. Atlanta: CDC; 2012 [acesso ago. 2012]. Disponível: http://www.cdc.gov/vaccines/vpd$\mathrm{vac} /$ polio/default.htm

41. Cornuz J, Senn N. Should influenza vaccine be compulsory for medical staff?. Rev Med Suisse. 2011;7(319):2323-4.

42. Girard DZ. Recommended or mandatory pertussis vaccination policy in developed countries: does the choice matter? Public Health. 2012;126(2):117-22.

43. Lantos JD, Jackson MA, Opel DJ, Marcuse EK, Myers AL, Connelly BL. Controversies in vaccine mandates. Curr Probl Pediatr Adolesc Health Care. 2010;40(3):38-58.

44. Colgrove J. The ethics and politics of compulsory HPV vaccination. N Engl J Med. 2006; 355(23):2389-91.

45. Malone KM, Hinman AR. Vaccination mandates: the public health imperative and individual rights. In: Goodman RA, Rothstein MA, Hoffman RE, editores. Law in public health practice. New York: Oxford University Press; 2003. p. 262-84.

46. Buchanan DR. Autonomy, paternalism, and justice: ethical priorities in public health. Am J Public Health. 2008;98(1):15-21.

47. Verweij $M$, Dawson A. Ethical principles for collective immunisation programmes. Vaccine. 2004;22(23-24):3122-6.

48. Chang R. Parity, interval value, and choice. Ethics. 2005;115:331-50.

49. Espinoza N, Peterson M. Risk and mid-level moral principles. Bioethics. 2012;26(1):8-14.

50. Salmon DA, Omer SB. Individual freedoms versus collective responsibility: immunization decisionmaking in the face of occasionally competing values. Emerg Themes Epidemiol. 2006;3:13.

51. McPhillips H, Marcuse EK. Vaccine safety. Curr Probl Pediatr. 2001;31(4):91-121.

52. Almeida JL, Schramm FR. Paradigm shift, metamorphosis of medical ethics, and the rise of bioethics. Cad Saude Publica. 1999;15(1 Suppl):S15-25.

53. Segre M. Reflections on bioethics: consolidation of the principle of autonomy and legal aspects. Cad Saúde Pública. 1999:15(15 Suppl):S91-8.

54. Schramm FR. Bioética da proteção em saúde pública. In: Fortes PAC, Zoboli ELCP, organizadores. Bioética e saúde pública. São Paulo: Loyola; 2003. p. 71-84.

55. Fine P, Eames K, Heymann DL. "Herd immunity": a rough guide. Vaccines. 2011;52(7):911-6.

56. Beauchamp TL, Childress JF. Princípios de ética biomédica. São Paulo: Loyola; 2002. p. 561.

57. Bradley P. Should childhood immunisation be compulsory? J Med Ethics. 1999;25(4):330-4.

58. Asveld L. Mass-vaccination programmes and the value of respect for autonomy. Bioethics. 2008;22(5):245-57.

59. Durand G. Introdução geral à bioética: história, conceitos e instrumentos. São Paulo: Loyola; 2003. p. 431.

60. Reichert TA, Sugaya N, Fedson DS, Glezen WP, Simonsen L, Tashiro M. The Japanese experience with vaccinating school children against influenza. N Engl J Med. 2001;344(12):889-96.

61. Piedra PA, Gaglani MJ, Kozinetz CA, Herschler G, Riggs M, Griffith M et al. Herd immunity in adults against influenza-related illnesses with use of the trivalent-live attenuated influenza vaccine (CAIV-T) in children. Vaccine. 2005;23(13):1540-8.

62. Looker $\mathrm{C}$, Kelly $\mathrm{H}$. No-fault compensation following adverse events attributed to vaccination: a review of international programmes. Bull World Health Organ. 2011;89(5):371-8.

63. Holland $\mathrm{M}$, Conte $\mathrm{L}$, Krakow $\mathrm{R}$, Colin L. Unanswered questions from the vaccine injury compensation program: a review of compensated cases of vaccine-induced brain injury. Pace Envtl L Rev. 2011;28(2):480-544. 
64. Hodges C. Nordic compensation schemes for drug injuries. J Consum Policy. 2006;29:143-75.

65. Brasil. Tribunal de Justiça de Minas Gerais. Ação de indenização por danos morais e materiais preliminares rejeitadas - ausência de comprovação do nexo de causalidade entre a vacinação e as sequelas da criança - impossibilidade de determinação ressarcitória pelo município - reforma da sentença. Apelação cível n 1.0684.07.002240-6/001-MG. Relator: Des. Silas Vieira. Tarumirim, 24 de setembro de 2009 [acesso 24 ago. 2012]. Disponível: http://www5.tjmg.jus.br/jurisprudencia/ pesquisaNumeroCNJEspelhoAcordao.do?numeroRegistro=1\&totalLinhas=1\&linhasPorPagina=1 $0 \&$ numeroUnico $=1.0684 .07 .002240-6 \% 2 \mathrm{F001} \&$ pesquisaNumeroCNJ=Pesquisar

66. Brasil. Tribunal de Justiça de Minas Gerais. Ação de indenização - vacina DTP tríplice lote contaminado - ausência de comprovação do nexo de causalidade entre a vacinação e a morte da criança - impossibilidade de determinação ressarcitória pelo Estado. Apelação cível $n^{\circ}$ 1.0611.02.001570-1/001-MG. Relator: Des. Silas Vieira. São Francisco, 30 nov. 2006 [acesso 24 ago. 2012]. Disponível: http://www5.tjmg.jus.br/jurisprudencia/ pesquisaNumeroCNJEspelhoAcordao.do?numeroRegistro=1\&total Linhas=1\&linhasPorPagina=1 0\&numeroUnico=1.0611.02.001570-1\%2F001\&pesquisaNumeroCNJ=Pesquisar

67. Brasil. Tribunal de Justiça de Minas Gerais. Responsabilidade objetiva - agente público causador do dano-dano moral não comprovado -improcedência da ação. Apelação cível n ${ }^{\circ} 1.0000 .00 .252994-$ 9/000-MG. Relator: Des. José Domingues Ferreira Esteves. 18 nov. 2002 [acesso 24 ago. 2012]. Disponível: http://www5.tjmg.jus.br/jurisprudencia/pesquisaNumeroCNJEspelhoAcordao.do ?numeroRegistro=1\&totalLinhas $=1 \&$ linhasPorPagina $=10$ \& numeroUnico $=1.0000 .00 .252994$ 9\%2F000\&pesquisaNumeroCNJ=Pesquisar

68. Brasil. Tribunal de Justiça do Rio Grande do Sul. Apelação cível n 70044599082-RS. Apelante: Thereza Borges Pedroso. Apelado: Município de Lajeado. Relator: Des. Ivan Balson Araújo. Rio Grande do Sul, 29 mar. 2012 [acesso 24 ago. 2012]. Disponível: http://www.tjrs.jus.br/ busca/?tb=proc

69. Brasil. Tribunal de Justiça de São Paulo. Responsabilidade civil do Estado - aquisição de poliomielite no curso da imunização obrigatória - inexistência de falha do serviço público, quer no tocante à atuação de seus agentes, quer na qualidade da vacina aplicada - risco da própria imunização, obrigatória em virtude de lei nacional, acentuado por fatores de ordem sanitária - ação julgada procedente - sentença reformada. Apelação cível n 639.645-5/6-SP. Relator: Coimbra Schmidt. São José do Rio Preto, 10 mar. 2008 [acesso 24 ago. 2012]. Disponível: https://esaj.tjsp.jus.br/ cjsg/consultaCompleta.do

70. Garrafa V. Da bioética de princípios a uma bioética interventiva. Bioética. 2005;13(1):125-34

71. Schramm FR, Kottow MH. Principios bioéticos en salud pública: limitaciones y propuestas. Cad Saúde Pública. 2001;17(4):949-56.

72. Schramm FR. A saúde é um direito ou um dever? Autocrítica da saúde pública. Revista Brasileira de Bioética. 2006;2(2)187-200.

73. Garrafa V, Porto D. Intervention bioethics: a proposal for peripheral countries in a context of power and injustice. Bioethics. 2003;17(5-6):399-416.

74. Garrafa V. Ampliação e politização do conceito internacional de bioética. Rev. bioét. (Impr.). 2012;20(1):9-20.

75. Garrafa V, Porto D. Bioética, poder e injustiça: por uma ética de intervenção. In: Garrafa V, Pessini L, organizadores. Bioética: poder e injustiça. São Paulo: Loyola; 2003. p. 35-43.

76. Schramm FR. Bioética da proteção: ferramenta válida para enfrentar problemas morais na era da globalização. Rev. bioét. (Impr.). 2008;16(1):11-23.

\section{Participação dos autores}

Sérgio de Castro Lessa elaborou o artigo. José Garrofe Dórea participou na correção e revisão crítica. 